\title{
P063. Colloid cysts of the third ventricle: a case report
}

\author{
Silvia de Pasqua*, Valentina Favoni, Giulia Giannini, Rossana Terlizzi, Giulia Pierangeli, Pietro Cortelli, Sabina Cevoli \\ From Abstracts from the 1st Joint ANIRCEF-SISC Congress \\ Rome, Italy. 29-31 October 2015
}

\section{Background}

Colloid cysts are rare congenital benign tumors accounting for $0.2-2 \%$ of all intracranial neoplasms. They usually occur in the front part of the third ventricle. The clinical presentation is related to the increased intracranial pressure and is widely variable; sudden death associated with acute hydrocephalus can occur, therefore recognition of this rare condition is important in order to select an appropriate surgical treatment. We report a case of new onset headache secondary to a colloid cyst of the third ventricle.

\section{Case report}

A 44-year-old woman with unremarkable medical history was admitted to our clinic for recurrent attacks of pressing headache, with abrupt onset and brief duration, accompanied by nausea, transient hearing loss and tinnitus. These symptoms were relieved by supine position. The clinical picture progressively worsened, with episodes of vomiting during headache. Neurological examination was negative. A magnetic resonance imaging (MRI) scan showed a spherical mass lesion with lipid signal at the intraventricular foramina of Monro causing compression of the third ventricle and expansion of the ventricular system, suggestive of hydrocephalus.

After neurosurgical evaluation the patient underwent an endoscopic removal of the lesion. Histological findings were compatible with colloid cyst of the third ventricle. After surgical treatment the patient recovered completely from symptoms and the follow-up MRI demonstrated the complete excision of the lesion.

\section{Conclusions}

Colloid cysts are congenital, slow growing, benign intraventricular lesions usually arising in the third ventricle.

\footnotetext{
*Correspondence: silvia.depasqua@hotmail.it Department of Biomedical and NeuroMotor Sciences (DIBINEM), Alma Mater Studiorum-University of Bologna, IRCCS Institute of Neurological Sciences of Bologna, Bologna, Italy
}

1. Ravnik J, Bunc G, Grcar A, Zunic M, Velnar T: Colloid cysts of the third ventricle exhibit various clinical presentation: a review of three cases. Bosn J Basic Med Sci 2014, 14(3):132-135.

2. Humphries RL, Stone CK, Bowers RC: Colloid cyst: a case report and 40(1):5-9.

3. Schwedt TJ, Matharu MS, Dodick DW: Thunderclap headache. Lancet Neurol 2006, 5(7):621-631.

\section{doi:10.1186/1129-2377-16-S1-A131}

Cite this article as: de Pasqua et al:: P063. Colloid cysts of the third ventricle: a case report. The Journal of Headache and Pain 2015 16(Suppl 1): A131. 